\title{
Effect of nanoparticles concentration on the characteristics of nanofluid sprays for cooling applications
}

MALÝ, M.; MOITA, A. S.; JEDELSKÝ, J.; RIBEIRO A. P. C.; MOREITA A. L. N.

Journal of Thermal Analysis and Calorimetry

2019, vol. 135, iss. 6, pp. 3375-3386

ISSN (Print): 1388-6150

ISSN (Online): 1588-2926

DOl: http://dx.doi.org/10.1007/s10973-018-7444-z

Accepted manuscript 


\title{
Effect of nanoparticles concentration on the characteristics of nanofluid sprays for cooling applications
}

\author{
M. Malý1 ${ }^{1}$ A. S. Moita ${ }^{2 *}$, J. Jedelsky ${ }^{1}$, A. P. C. Ribeiro ${ }^{3}$, A. L. N. Moreira ${ }^{2}$
}

1. Faculty of Mechanical Engineering, Brno University of Technology, Technicka 2896/2, Brno 61669, Czech Republic.

2. IN+ - Center for Innovation, Technology and Policy Research, Instituto Superior Técnico, Universidade de Lisboa, Av. Rovisco Pais, 1049-001 Lisboa, Portugal.

3. Centro de Química Estrutural, Instituto Superior Técnico, Universidade de Lisboa, Av. Rovisco Pais, 1049-001 Lisboa, Portugal

Corresponding author:

A.S. Moita (anamoita@tecnico.ulisboa.pt)

ORCID ID: 0000-0001-9801-7617

Phone: +351-21 8417876

Fax: +351-21 8496156

Address: IN+ - Center for Innovation, Technology and Policy Research, Instituto Superior Técnico, Universidade de Lisboa, Av. Rovisco Pais, 1049-001 Lisboa, Portugal.

Abstract: This study addresses the effect of nanofluid synthesis on the rheological 
properties of the resulting fluid and their consequent effect on the characteristics (size and velocity distribution of droplets, spray cone angle, etc.) of the sprayed nanofluids. The results are discussed in the light of how the spray characteristics affect the use of the resulting nanofluid spray for cooling purposes. Nanoparticles of alumina $\left(\mathrm{Al}_{2} \mathrm{O}_{3}\right)$ and Zinc Oxide $(\mathrm{ZnO})$ are mixed in water-based solutions, for concentrations varying between $0.5 \%$ and $2 \%$ wt for alumina and between $0.01 \%$ and $0.1 \%$ wt for the zinc oxide particles. $\mathrm{FeCl}_{2} \cdot \mathrm{HH}_{2} \mathrm{O}(\mathbf{0 . 1 \%} \mathrm{wt})$ was also used to infer on the effect of the nature (material) of the particles in the physico-chemical properties of the resulting solutions. Among the various surfactants tested, citric acid (0.15\%) was chosen for the final working mixtures, as it assured a stable behaviour of the solutions prepared during the entire study. The nanoparticles were characterized in detail, and the physico-chemical properties of the fluid were measured before and after atomization, to evaluate any possible particle loss in the liquid feeding system or retention in the atomizer. The nanofluids were sprayed using a pressure-swirl atomizer at $0.5 \mathrm{MPa}$ injection pressure. Droplet size and velocity in the spray were probed using Phase Doppler Anemometry. For the range of experimental conditions covered here, the results show that liquid viscosity is an important parameter in predetermining the spray characteristics of nanofluids, as it affects the primary liquid breakup. Despite this, only a mild increase is observed in the nanofluids viscosity, mainly for higher concentrations of alumina, which was not sufficient to significantly affect the spray characteristics, except for a small decrease in the spray cone angle and the size of the atomized droplets. Hence, for cooling purposes, the atomization mechanisms are not compromised by the addition of the nanoparticles and their using is beneficial, as they enhance the thermal properties without a significant deterioration of other fluid properties such as viscosity and spray characteristics. Spray characteristics promote liquid adhesion to the cooling surfaces 
and droplet size and velocity are kept within a range that is appropriate for spray cooling, following the literature recommendations and our analysis.

Keywords: Nanofluids, Pressure-swirl atomizer, Spray, PDA,

Abbreviations

SCA spray cone angle $\left({ }^{\circ}\right)$

SPAN relative span $(-)$

\section{List of symbols}

$D_{20} \quad$ surface mean diameter $(\mathrm{m})$

$D_{30} \quad$ volume mean diameter (m)

$D_{32} \quad$ Sauter mean diameter $(\mathrm{m})$

$D_{v 0.1} \quad 10 \%$ volume diameter $(\mathrm{m})$

$D_{v 0.5} \quad 50 \%$ volume diameter (m)

$D_{v 0.9} \quad 90 \%$ volume diameter $(\mathrm{m})$

$f \quad$ data rate $(\mathrm{Hz})$

$I D_{32}$ integral Sauter mean diameter (m)

$r \quad$ radial distance $(\mathrm{mm})$

Re Reynolds number (-)

$U$ axial velocity component $\left(\mathrm{m} \cdot \mathrm{s}^{-1}\right)$

We Weber number (-) w liquid velocity at the exit orifice $\left(\mathrm{m} \cdot \mathrm{s}^{-}\right.$

1)

Z axial distance (m)

Greek characters

$\mu_{l} \quad$ liquid dynamic viscosity $\left(\mathrm{kg} \cdot \mathrm{m}^{-1} \cdot \mathrm{s}^{-1}\right)$

$\rho_{l} \quad$ liquid density $\left(\mathrm{kg} \cdot \mathrm{m}^{-3}\right)$

$\sigma_{l} \quad$ liquid/gas surface tension $\left(\mathrm{kg} \cdot \mathrm{s}^{-2}\right)$

\section{Introduction}


Dissipating high heat loads is currently a challenge in many industrial applications, such as metallurgy, food processing, microelectronics, or even in solar energy applications e.g. [1-3]. As for the various liquid cooling techniques explored by the researchers within the last two decades, spray cooling is among the most popular, given the high heat transfer coefficients that can be achieved (of the order of $10^{4}-10^{5} \mathrm{~W} / \mathrm{m}^{2} \mathrm{~K}$ or higher - [4]). Nevertheless, the efficient implementation of this strategy must cope with the increasingly demanding heat loads that are dissipated, so that continuous efforts have been put to further enhance the heat transfer processes. In this context, several authors addressed surface modification to enhance these processes, e.g. [2,4], while others have explored the use of nanofluids to reach the same goal [5]. However, while many of these researchers dealt with nanofluids as being a single-fluid with novel thermo-physical properties, mostly focusing on the effect of the nanoparticles addition on the thermal properties of the fluids [6-13] and on the heat transfer processes, often addressing convective heat transfer in internal flows [14-21], research on nanofluid droplets/sprays impacting on heated surfaces is still limited e.g. $[8,10]$ and the actual effects of adding nanoparticles in the fluid flow characteristics and, particularly in the mechanisms of atomization, are still scarcely reported. Hydrodynamic behaviour of the nanofluids slightly differs from that of the pure liquids, which is mainly related to physical modifications of the local and of the bulk properties of the nanofluids. Surface tension is affected by the nanoparticle concentration and size. Although this effect is less prominent in the bulk properties [22], it can be relevant for the wettability at the liquid-solid interface [23-24]. The liquid density is expected to be slightly increased, as the nanoparticles have usually higher density compared to the base liquid. The viscosity of nanofluids depends on the size, shape, concentration and material of the added nanoparticles. Moreover, those parameters also determine if the 
nanofluids behave as Newtonian or non-Newtonian liquids. For instance, nanofluids with spherical particles are more likely to depict a Newtonian behaviour [25]. However, nanofluids rheology is a complex topic, as evidently shown in several studies reporting contradictory results. For instance, Jang et al. [26] report a dependency of the nanofluid viscosity on the tube size of flow domain at the microscale, which was neglected by other authors [27]. However, the wall friction coefficient is reported by others to slightly increase with the addition of nanoparticles [28].

Since all these properties are likely to affect the spray characteristics, a detailed characterization of the spray plays a paramount role in the heat transfer processes given the intricate correlation existing between droplet/spray characteristics and heat transfer processes. The pressure-swirl atomization excels in the generation of fine droplets at relatively low liquid pressure. In principle, the liquid is injected via tangential ports into a swirl chamber. The swirled liquid then leaves the exit orifice and spreads as a conical liquid sheet outside the atomizer. The liquid sheet consequently breaks up due to aerodynamic forces. The parameters of resulting droplets are dependent on the liquid sheet thickness and velocity. However, due to the complexity of the whole process, it is impossible to analytically predict the droplet sizes as they depend on the atomizer geometry, liquid properties and operating conditions. Many studies investigated the effect of liquid properties on the spray characteristics. Probably the most complex review of published work was reported by Lefebvre and McDonell [29]. Such studies mostly reveal that the liquid density has only a negligible role as its variation is usually small. The surface tension and the liquid viscosity have a similar impact on the atomization; however, both of them act differently. Hence, viscosity has a dominant effect on the liquid sheet breakup - a primary breakup. Its relative importance decreases in the region of the secondary breakup where the surface tension 
plays a dominant role. However, from the literature reviewed, the only known study related to the spray characteristics of nanofluids was conducted in 2017 by Kannaiyan and Sadr [30]; it concerns the effect of the concentration of alumina particles in kerosene.

In line with this, the present study addresses the effect of nanofluid synthesis on the local physical properties of the resulting nanofluid and their consequent effect on the atomization characteristics (droplet size and velocity distribution and spray angle, among others). The nature and the concentration of the nanoparticles of the based fluid are taken as influencing parameters, giving a particular emphasis on their effect on the interfacial mechanisms present in atomization. The results presented and discussed here focus on the consequences of the nanoparticle concentration on the atomization characteristics and how they can potentially affect the use of the resulting spray for cooling. Indeed, the cooling performance of the spray is strictly related to the complex interactions between droplets-droplets, droplets-spreading lamellas and droplets-deposited liquid film [12], particularly when a liquid phase change occurs, as a strong deposit of cold liquid may preclude the occurrence of phase change. In this case, the liquid renovation by droplet impingement may play an additional and important role in removing the heat flux, essentially by a convective single-phase process [1-2]. Hence, fine/disperse sprays such as that used in the present work, may be preferred [1,31] with optimized intermittent cycles, to better disperse the spray on the cooling area and to allow droplet spreading into thin lamellas, thus promoting liquid phase change [32-33]. In such case, the impact outcomes (e.g. whether the droplet spreads or disintegrates after the impact) are directly dependent on the initial droplets sizes and velocities within the impinging spray. In any case, characterizing the spray prior to impact is mandatory, as characteristic size and velocity values of the spray droplets are directly used to compute representative non-dimensional numbers (Weber, Nusselt and 


\section{Reynolds numbers, among others) [1-2,32-33].}

\section{Experimental procedure}

Different nanofluids, obtained from alumina, zinc, copper and iron oxides in water are synthesized using co-precipitation and solvothermal methods [34], as detailed in the following section and are used to produce the sprays characterised in the present work.

The tested atomizer is a pressure-swirl type, as shown in Fig. 1. The atomizer is smallsized, with a discharge orifice of $0.42 \mathrm{~mm}$ in diameter and two tangential inlet ports with a square cross-section of $0.6 \times 0.6 \mathrm{~mm}^{2}$.

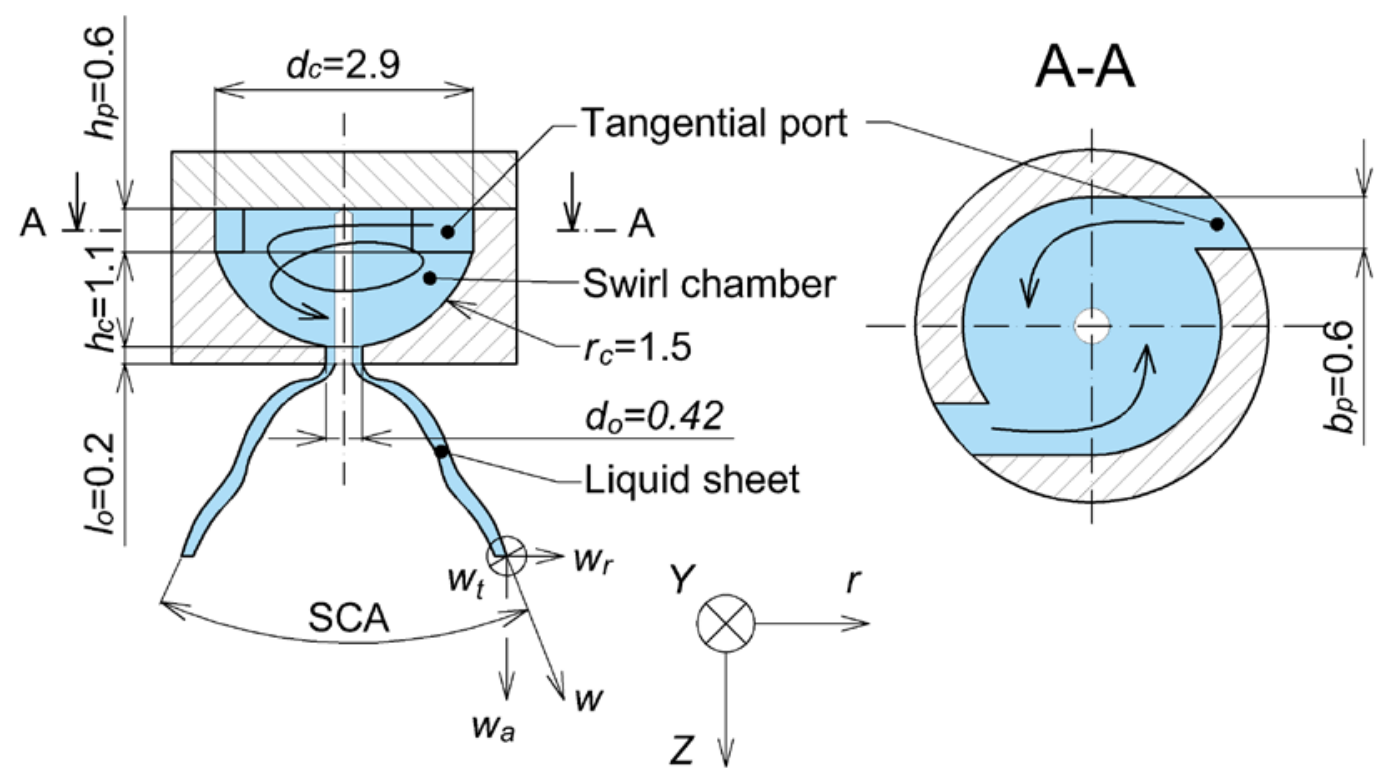

Fig. 1 Schematic of the pressure-swirl atomizer.

The liquid was supplied from a small (3 l) pressure vessel, pressurised by air at 0.5 MPa. The liquid mass flow rate through the atomizer was approx. $7 \mathrm{~kg} / \mathrm{h}$. The atomized liquid was captured in a collection chamber and consequently re-used.

\section{Preparation of nanofluids and characterisation of their thermophysical properties}

A two-step process was used to prepare the nanofluids. The mixtures were prepared in 
the range of 0.01 to $2 \%$ weight percentages, mixed up on a base fluid of deionised water (DI) and a surfactant and were placed in the ultrasonic bath for $1 \mathrm{~h}$. The characteristic sizes of the nanoparticles, which were mainly acquired from Fluka and from Sigma Aldrich are summarized in Table 1. The main composition of the resulting solutions is shown in Table 2.

Table 1. Specification of the nanoparticles size.

\begin{tabular}{lcl}
\hline Samples & Diameter/nm & Brand \\
\hline $\mathrm{Al}_{2} \mathrm{O}_{3}$ & 80 & Fluka \\
$\mathrm{ZnO}$ & 80 & Sigma Aldrich \\
$\mathrm{CuO}$ & 50 & Sigma Aldrich \\
$\mathrm{FeCl}_{2} \cdot 4 \mathrm{H}_{2} \mathrm{O}$ & $\geq 100$ & Sigma Aldrich \\
\hline
\end{tabular}

Table 2. Specification of the nanofluids composition. 


\begin{tabular}{|c|c|c|c|c|c|}
\hline \multirow{3}{*}{$\begin{array}{l}\text { Sample } \\
\text { number } \\
1\end{array}$} & \multicolumn{5}{|c|}{ Weight percentage/\% } \\
\hline & \multicolumn{2}{|c|}{ Surfactant } & \multicolumn{2}{|l|}{ Oxide } & $\begin{array}{c}\text { Deionized } \\
\text { water }\end{array}$ \\
\hline & Citric acid & 0.15 & - & & $\begin{array}{l}99.85 \\
\text { (pure) }\end{array}$ \\
\hline 2 & Citric acid & 0.15 & $\mathrm{Al}_{2} \mathrm{O}_{3}$ & 2 & $\begin{array}{l}97.85 \\
\text { (pure) }\end{array}$ \\
\hline 3 & Citric acid & 0.15 & $\mathrm{Al}_{2} \mathrm{O}_{3}$ & 0.5 & $\begin{array}{l}99.35 \\
\text { (pure) }\end{array}$ \\
\hline 4 & Citric acid & 0.15 & $\mathrm{ZnO}$ & 0.5 & $\begin{array}{l}99.35 \\
\text { (pure) }\end{array}$ \\
\hline 5 & Citric acid & 0.15 & $\mathrm{ZnO}$ & 0.01 & $\begin{array}{l}99.84 \\
\text { (pure) }\end{array}$ \\
\hline 6 & Citric acid & 0.15 & $\mathrm{CuO}$ & 0.1 & $\begin{array}{l}99.75 \\
\text { (pure) }\end{array}$ \\
\hline 7 & Citric acid & 0.15 & $\mathrm{FeCl}_{2} \cdot 4 \mathrm{H}_{2} \mathrm{O}$ & 0.1 & $\begin{array}{l}99.75 \\
\text { (pure) }\end{array}$ \\
\hline
\end{tabular}

As briefly explained in the introduction, particular interaction phenomena may occur at the interface between the nanoparticles and the surface to cool during spray impact. However, prior to impact, and for the low concentrations used in this study, the main influence of the particles on the spray is related to the possible sedimentation and agglomeration, which may locally affect the thermal and the physico-chemical 
properties of the solutions. In all samples, the dispersion was observed and maintained when a surfactant was added to the mixture. Different surfactants were tested (e.g. citric acid, oleic acid, CTAB - Cetyl trimethylammonium bromide) to infer on their effect in the stability of the nanofluids. The mixtures showing the most stable behaviour were prepared with citric acid; therefore those mixtures were used to show the results presented and discussed here. The stability of the low concentrated nanofluids (up to $0.5 \mathrm{wt} \%$ ) was achieved within hours, then sedimentation was observed. However, the nanofluid with $2 \mathrm{wt} \%$ of $\mathrm{Al}_{2} \mathrm{O}_{3}$ had a limited stability as the sedimentation appears in approx. 15 minutes. The measurement duration was about 10 minutes for one liquid batch, so it was not affected by sedimentation. After hand re-shacking, the sedimented part was dissolved, and the stability was restored. In order to prevent the sedimentation, the liquid supply vessel was shaken every minute.

The morphology was analysed by scanning and transmission electron microscopy, which also gives information about the phase structures and chemical composition, complemented by Fourier transform infrared spectroscopy, X-ray diffraction, Raman and X-ray photoelectron spectroscopy. Surface wetting was then quantified with an optical tensiometer (THETA from Attension), by the apparent equilibrium and quasi-static advancing and receding macro-contact angles, following the procedures described in [3536]. The accuracy of the contact angle measurements is of the order of $\pm 1^{\circ}$. Care was taken to perform a high number of measurements (of the order of 15 measurements) for which the values dispersion was at most of the order of $\pm 5^{\circ}$.

As for the thermophysical properties of the nanofluids, the present study considered the measurement of the density $\rho_{l}$, dynamic viscosity $\mu_{l}$ and surface tension $\sigma$. The density was evaluated from the concentration of the solution, by mass conservation principles and was very close to that of water, for all the samples tested $\left(\rho_{l}=998 \mathrm{~kg} / \mathrm{m}^{3}\right)$. The viscosity 
was evaluated with an ATS RheoSystems (a division of CANNON ${ }^{\circledR}$ Instruments, Co) under controlled temperature conditions, with an accuracy of $\pm 5 \%$. The surface tension was measured under controlled temperature conditions $\left(20 \pm 2^{\circ} \mathrm{C}\right)$ with an optical tensiometer THETA(Attention), using the pendant drop method. The value taken for the surface tension of each solution was averaged from 15 measurements, with a maximum standard deviation of the mean of $\mathbf{0 . 0 4} \mathbf{~ m N m}^{-1}$. A detailed description of the measurement procedures is provided in [37].

The properties of the nanofluids were measured before and after atomization, since if particle trapping would occur in the liquid feeding system or in the atomizer, it would affect the properties of the fluids and the atomization mechanisms. Also, the images taken with the high-speed camera were qualitatively analysed to check for possible modifications in the spray morphology caused by any significant loss of particles. No significant changes were observed, either in the liquid properties or in the spray morphology that could indicate any problem related to the loss of particles.

\section{Spray characterisation}

The measurements of droplets velocity and size were performed using a two-component Phase Doppler anemometer by Dantec Dynamics A/S (Skovlunde, Denmark) which consists of 55x transmitting optics, 57x10 receiving optics and multi-line Ar-Ion+ laser Spectra-Physics type 177-G0232. The optical configuration is summarized in Table 3. Burst signal processor P80 was used to process the measured signal. BSA flow software v5.20 was used to control the data acquisition and the following setting was used: Photomultiplier sensitivity $1180-1500 \mathrm{~V}$, signal gain $22 \mathrm{~dB}$, velocity centre $15 \mathrm{~ms}^{-1}$, velocity span $30 \mathrm{~ms}^{-1}$. Although the PDA is capable of 2D measurement, only the axial velocity component $U$ was evaluated for this part of the study. 
The measurement grid uses a radial system, as defined in Fig. 2, where $r=0 \mathrm{~mm}$ corresponds to the centre of the spray cone. Measurements are reported for $Z=10 \mathrm{~mm}$ and $Z=20 \mathrm{~mm}$, being $Z=0 \mathrm{~mm}$, positioned at the atomizers exit orifice. Extensive measurements were then performed for $-20 \mathrm{~mm}<r<20 \mathrm{~mm}$ and $-20 \mathrm{~mm}<y<20 \mathrm{~mm}$ in $2 \mathrm{~mm}$ steps on two radially orthogonal axes. The measurement was limited to 50000 samples acquired or to 15-second acquisition duration at each measured point.

Table 3. Outline of the phase Doppler optical configuration.

\begin{tabular}{ll}
\hline Transmitting optics & Value \\
Laser power/mW & 400 \\
Laser wavelengths/nm & 514 and 488 \\
Beam spacing/mm & 60 \\
Frequency shift/MHz & 40 \\
Transmitter focal length/mm & 310 \\
& \\
Receiving optics & 69 \\
Scattering angle/ & \\
Receiver focal length/mm & 500 \\
Micrometer/mm & 0.500 \\
\hline
\end{tabular}

Characteristic droplet sizes statistically evaluated from the sampled droplets include average values and characteristic diameters representing the volume ratios and the area to volume ratios. These characteristic diameters are usually more representative of the actual 
droplet size distribution across the spray, as they weigh the relative importance of larger droplets. These characteristic diameters are also important as they can help us to understand the most suitable spray characteristics promoting heat transfer.

The present work mostly evaluates the Sauter Mean Diameter or $D_{32}, D_{V 0.1}, D_{V 0.5}$ and $D_{V 0.9}$. The quantities $D_{V 0.1}, D_{V 0.5}$ and $D_{V 0.9}$ represent the particle diameters below which $10 \%, 50 \%$ and $90 \%$, respectively, of the total volume is contained. The Sauter mean diameter or $D_{32}$ is the ratio between the area and the volume of the droplets measured. From this, the Integral Sauter mean diameter $\left(I D_{32}\right)$ can be calculated as a single parameter providing the global representation of $D_{32}$ by its mass weighted averaging over the entire radial profile [38]:

$$
I D_{32}=\sum_{i=1}^{n} r_{i} f_{i} D_{30, i}^{3} / \sum_{i=1}^{n} r_{i} f_{i} D_{20, i}^{2}
$$

where $f_{i}$ is data-rate, $D_{30}$ is volume mean diameter and $D_{20}$ is surface mean diameter in the position with radial distance $r_{i}$ from the atomizer centre.

There are many aspects which affect the precision of the PDA measurement e.g.: fluctuations in the operating pressure of the atomizer, uncertainty of the atomizer positioning respective to the PDA measurement volume and the error of the PDA instrument itself. As it is almost impossible to evaluate these phenomena separately, standard deviations (SD) of main evaluated parameters were calculated as quantities revealing the repeatability error. This procedure was based on five measurements with pure water. Those measurements were performed randomly during the measurement series. The SD was found to be $\pm 0.2-1 \mathrm{~ms}^{-1}$ for velocity, depending on the measurement position, \pm 1-3.5 $\mu \mathrm{m}$ for $D_{32}, \pm 1.5 \mu \mathrm{m}$ for $I D_{32}$ and $\pm 1.5^{\circ}$ for PDA based measurements of the Spray Cone Angle (SCA). The error bars are not displayed in the plots for clarity, as the variation of the results is low. 
The nanofluids with a nanoparticle concentration of $0.5 \mathrm{wt} \%$ or higher were optically opaque. Spherical validation was about $75-85 \%$ for the opaque liquids which is slightly lower compared to the validation rate of $88-92 \%$ of transparent liquids. As long as the inhomogeneities inside the droplets are small compared with the wavelength of the laser light (514 nm), the measurement accuracy should be undisturbed [39], but signal blur may occur and decrease the validation and data rate.

High-speed visualization using a high-speed camera Phantom v4.2 and image postprocessing complement the PDA measurements to qualitatively characterize the shape and morphology of the sprays and to evaluate the SCA. Images were taken at $15 \mathrm{kHz}$, with a resolution of $192 \times 192 \mathrm{px}^{2}$. The SCA was captured by an in-house MATLAB code based on the Canny edge detector.

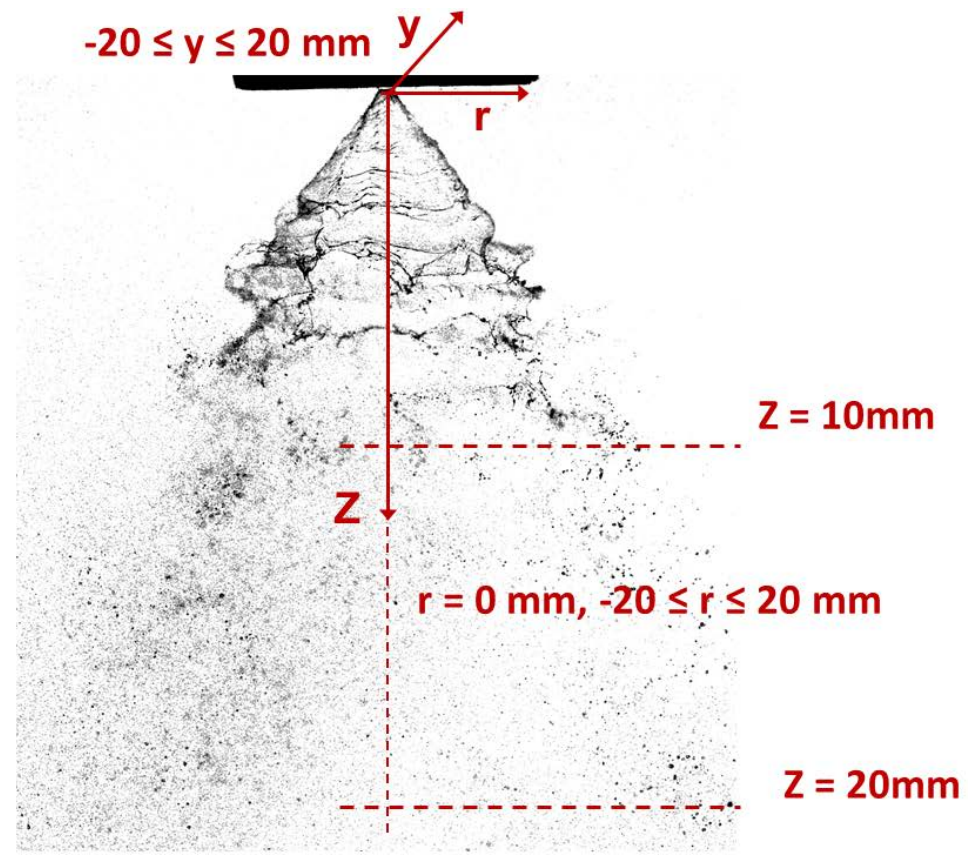

Fig. 2 System of coordinates used in the measurements with the phase Doppler anemometer.

\section{Results and discussion}

The first part of this study evaluates the effect of nanoparticles concentration on the 
thermophysical properties of the nanofluids. Then, it is followed by the analysis of their consequent effects on the spray characteristics and how they can affect the suitability of the spray for cooling applications. Hence, this possible effect was firstly evaluated in the surface tension and in the viscosity, as they are paramount properties affecting the spray angle and the atomization processes. The results in Fig. 3 show a minor influence of the nanoparticles concentration on the surface tension of the mixtures (Fig. 3a), but evidence a trend of the viscosity to increase with the particles concentration (Fig. 3b), particularly when the alumina particles are used.

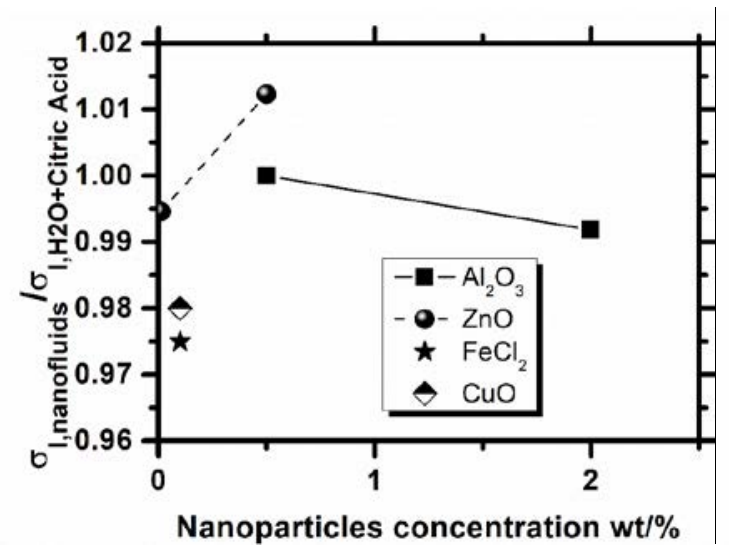

a)

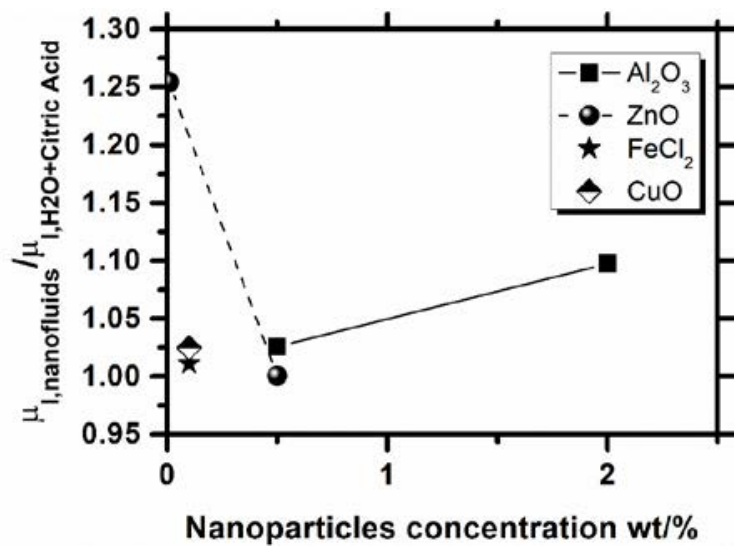

b)

Fig. 3 Effect of the nanoparticles concentration on: a) surface tension of the nanofluids, b) dynamic viscosity of the nanofluids.

The properties of the nanofluids resulting from the mixture with the copper and iron oxide particles show no significant effect of adding the nanoparticles on the properties of the resulting solution. So, for the solution water+ $\mathrm{CuO}(0.1 \%)+\mathrm{Citric}$ acid $(0.15 \%)$, the surface tension was measured to be $72 \mathrm{mN} \cdot \mathrm{m}^{-1}$ and the dynamic viscosity was $1.05 \mu / \mathrm{mPa}^{-1} \cdot \mathrm{s}^{-1}$. For the solution water+ $\mathrm{FeCl}_{2} \cdot 4 \mathrm{H}_{2} \mathrm{O}(0.1 \%)+$ citric acid $(0.15 \%)$, the surface tension was $71 \mathrm{mN} \cdot \mathrm{m}^{-1}$, while the dynamic viscosity was 1.04 $\mu / \mathrm{mPa}^{-1} \cdot \mathrm{s}^{-1}$. 
The surface tension and the viscosity of the mixtures are divided by the values of the base liquid (water+surfactant) to isolate the effect of adding the nanoparticles from that of adding the surfactant. This effect of the nanoparticles on the nanofluids viscosity agrees with several studies in the literature, e.g. [10]. However, the variation of surface tension was less than 3\%; thus, this effect can be neglected.

The possible effect of the liquid viscosity on the spray characteristics, the SCA, droplets characteristic sizes and representative velocities were analysed. SCA, was determined both from the high-speed images and from the PDA measurements (Fig. 4). The measures taken from the post-processing of the high-speed images were mainly used to validate the PDA measurements.

The PDA based SCA was determined as the apex angle of a virtual cone which covers $90 \%$ of the liquid volume flux inside the spray. It was derived from a radial profile of the normalised cumulative liquid distribution across the spray (Fig. 5). Thus the SCA values taken from the PDA measurements do not match perfectly to those obtained from the highspeed images. However, the differences between the extreme angle values are very small - $2 \%$ for camera-based SCA and 6\% for PDA based SCA, which allows validating the PDA measurements. A linear correlation with correlation coefficient $R^{2}=0.85$ shown in Fig. 4 can be obtained. 


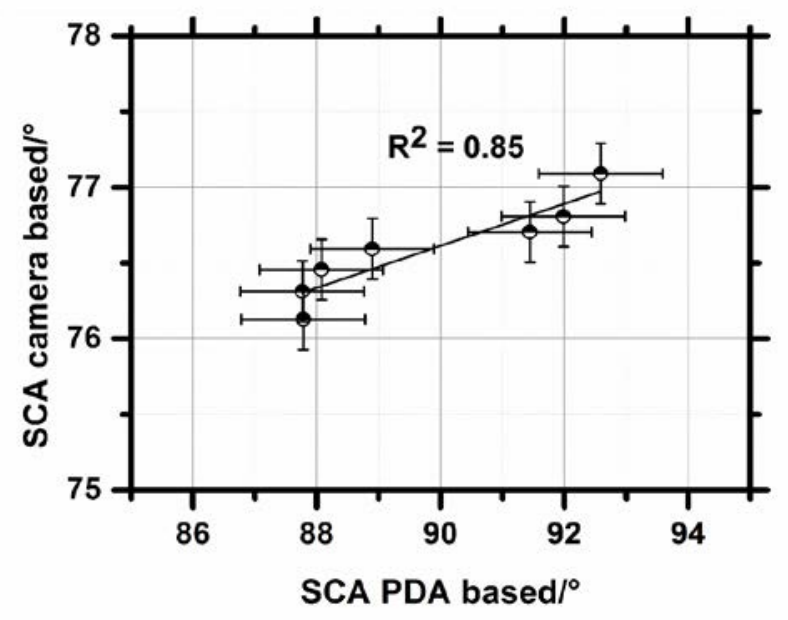

Fig. 4 Comparison between the SCA values evaluated from the PDA measurements and taken from the post-processing of the high-speed images.

The liquid sheet breakup length based on the high-speed images was about 5-7 mm with no obvious correlation with the nanofluid used. The image resolution was not sufficient to distinguish it more precisely. The PDA measurements at $Z=10 \mathrm{~mm}$ are conducted just after the primary breakup.

Each nanofluid was atomized and measured several times. However, the spray characteristics were slightly different between the first and the second measurement. This effect is illustrated in Fig. 5, for the nanofluid obtained with $0.01 \%$ wt of $\mathrm{ZnO}$ particles, where the liquid distribution in the spray is shifted towards the spray centre for the first measurement. Similar behaviour was observed for all the nanofluids tested here. Hence, for further analysis, only the first measurement is considered, which nevertheless is still statistically representative [40].

Fig. 6 shows the evolution of the axial velocity and $D_{32}$ along the spray radial coordinate, at $Z=20 \mathrm{~mm}$. The axial velocity reaches its maximum in the positions where the liquid sheet is expected $(r=6-8 \mathrm{~mm})$. This velocity profile is typical for pressure-swirl atomizers. From the figure, it can be inferred that higher nanoparticles concentration tends 
to form a spray with lower axial velocities and smaller droplets, especially in the spray centre where, however, there is a very low droplet mass flow rate (see Fig. 7). $\mathrm{Al}_{2} \mathrm{O}_{3}$ with $2 \mathrm{wt} \%$ presents the lowest values of both the axial velocity and $D_{32}$, being followed by $\mathrm{Al}_{2} \mathrm{O}_{3}$ with $0.5 \mathrm{wt} \%$ and $\mathrm{ZnO} 0.5 \mathrm{wt} \%$. These differences become less relevant as the measurements were performed further from the spray centre. These results are in agreement with those reported in [30] where the nanofluids with higher concentration formed droplets with lower axial velocity and slightly lower $D_{32}$.

The droplet size and velocity are linked together, as larger droplets have higher momentum and thus their velocity remains high, further downstream from the atomizer.

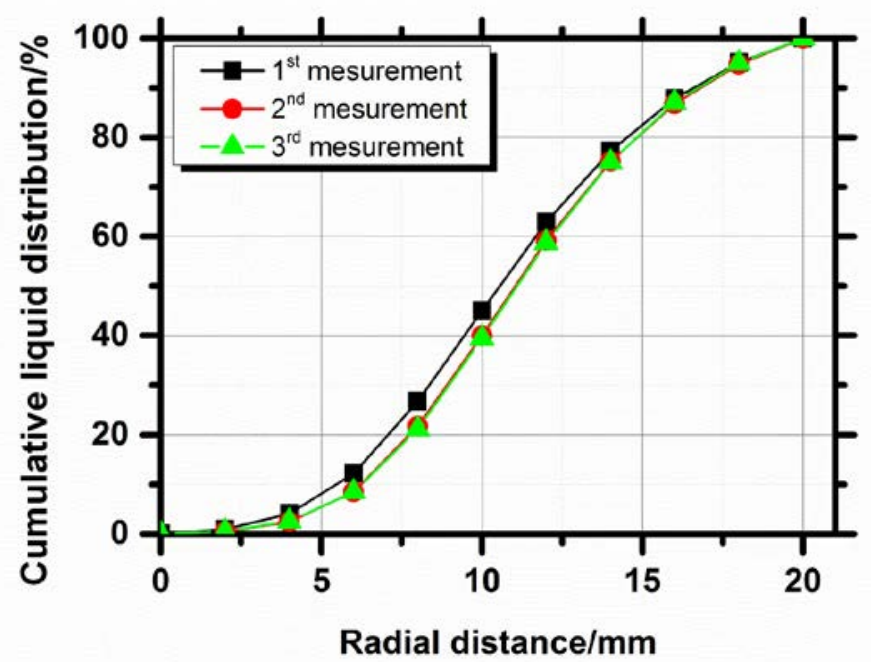

Fig. 5 Cumulative liquid distribution in the spray for three consequent measurements using ZnO 0.01\% wt. 


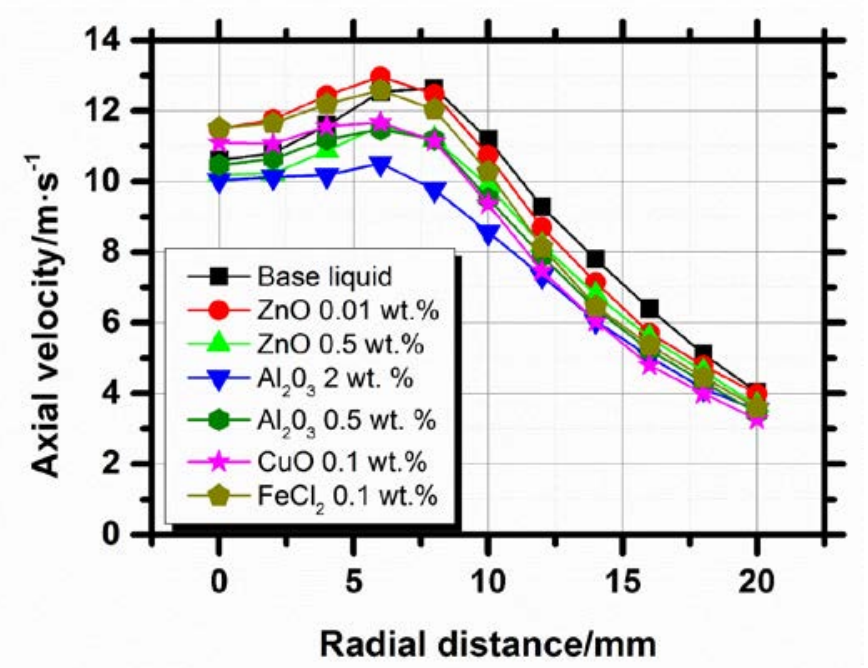

a)

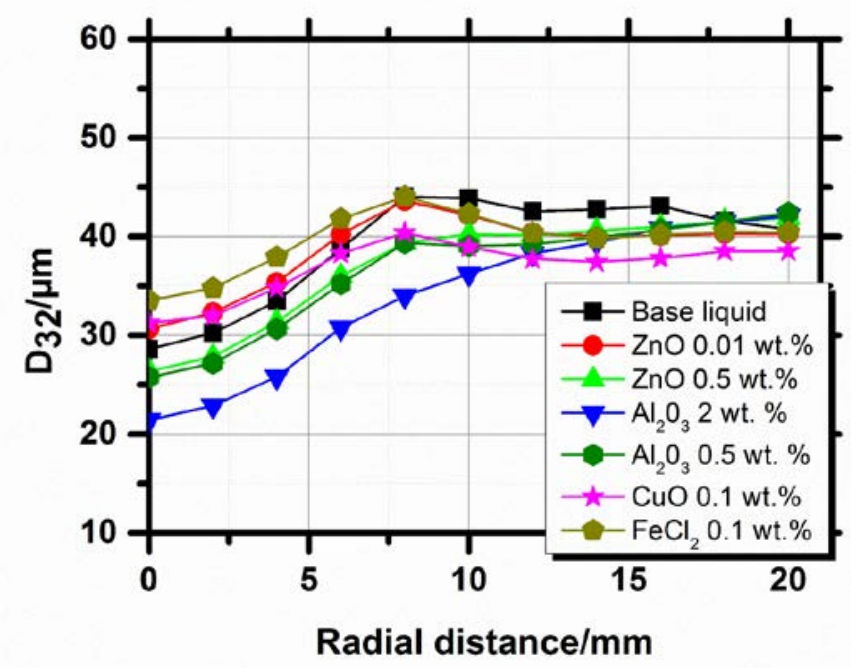

b)

Fig. 6 Spray profile characteristics measured at $Z=20 \mathrm{~mm}$ : evolution of a) Droplets axial velocity and of b) $D_{32}$ along the radial coordinate of the spray.

The liquid volume distribution across the spray, as illustrated in Fig. 7, shows a negligible effect of the nanoparticle concentration. Hence, mild differences are only observed for the largest nanoparticle concentration ( $2 \mathrm{wt} \%$ ), for which there is more liquid concentrated further from the spray centre. This is evident for both axial distances $(Z=10$ and $20 \mathrm{~mm}$ ). For $Z=10 \mathrm{~mm}$, both nanofluids with $0.5 \mathrm{wt} \%$ have a slightly more liquid 
concentrated further from the spray centre. This is not evident for higher axial distance. Thus, the same amount of the liquid is distributed along the radial axis even when the droplets have a slightly different characteristic $D_{32}$ or axial velocities. The highest liquid flow rate at $Z=20 \mathrm{~mm}$ was found at $r=10-14 \mathrm{~mm}$ where $D_{32}$ (Fig. 6) was almost independent of the liquid used. However, the axial velocity reached a maximal value at $r=6-8 \mathrm{~mm}$ which corresponds to the inner edge of the liquid sheet as the liquid flow rate sharply increases in those positions.

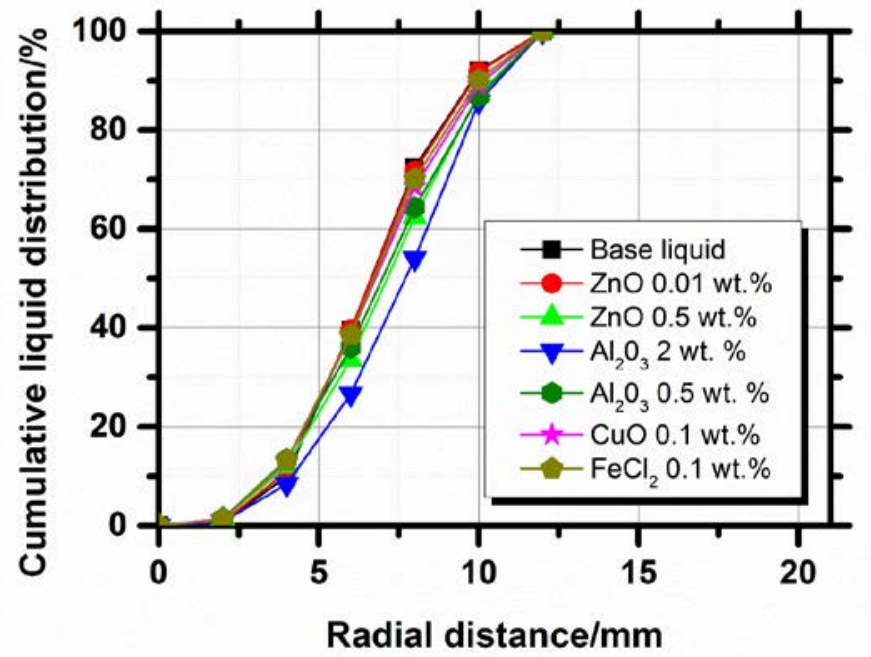

a)

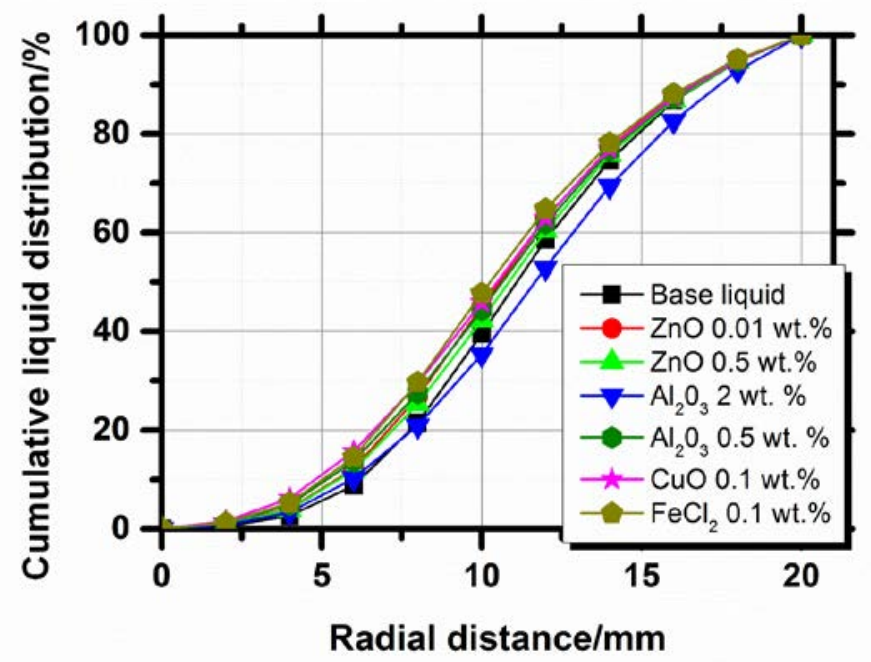

b) 
Fig. 7 Liquid volume distribution across the spray (i.e. along the radial coordinate $r$ ) at: a) $Z=10 \mathrm{~mm}$ and b) $Z=20 \mathrm{~mm}$.

A clearer perspective of the liquid distribution can be provided by the fractional volume diameters, which, as aforementioned, represent the particle diameters below which $10 \%$ ( $\left.D_{V 0.1}\right), 50 \%\left(D_{V 0.5}\right)$ or $90 \%\left(D_{V 0.9}\right)$ of the total volume is contained - see Fig. 8 . Therefore, $D_{V 0.1}$ represents a volume fraction of the smallest particles. In the spray centre, up to $r=10 \mathrm{~mm}$, the nanofluids with the highest nanoparticle concentration have a larger fraction of smallest droplets. For positions further than $r=10 \mathrm{~mm}$, all the nanofluids tested depicted a very similar $D_{V 0.1}$. On the other hand, $D_{V 0.9}$ which is mostly affected by large particles depicts a similar trend to that shown by $D_{32}$ : $D_{V 0.9}$ reaches a maximal value at $r=8 \mathrm{~mm}$ as there are large droplets in the disintegrated liquid sheet. For the positions on the very edge of the spray, the highly concentrated nanofluids have a relatively larger $D_{V 0.9 \text {, }}$ which indicates a higher number of large droplets. This trend is in agreement with the small increase in $D_{32}$ for these nanofluids in Fig. 6 .

Relative SPAN, calculated as $\operatorname{SPAN}=\left(D_{v 0.9}-D_{v 0.1}\right) / D_{v 0.5}$ was also evaluated but showed only small deviations with no obvious correlation with the nanofluid used.

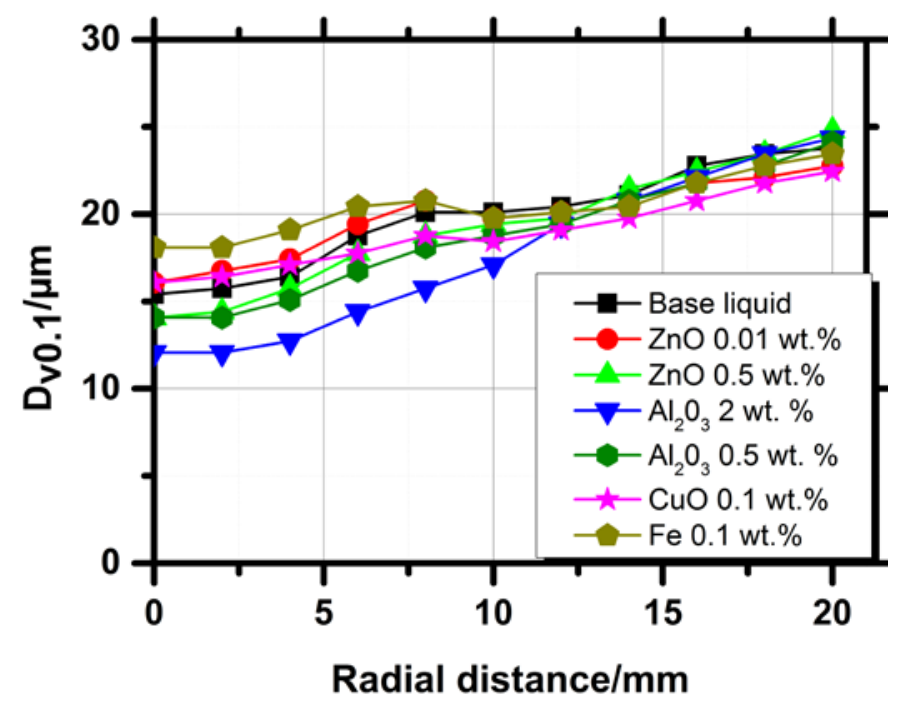


a)

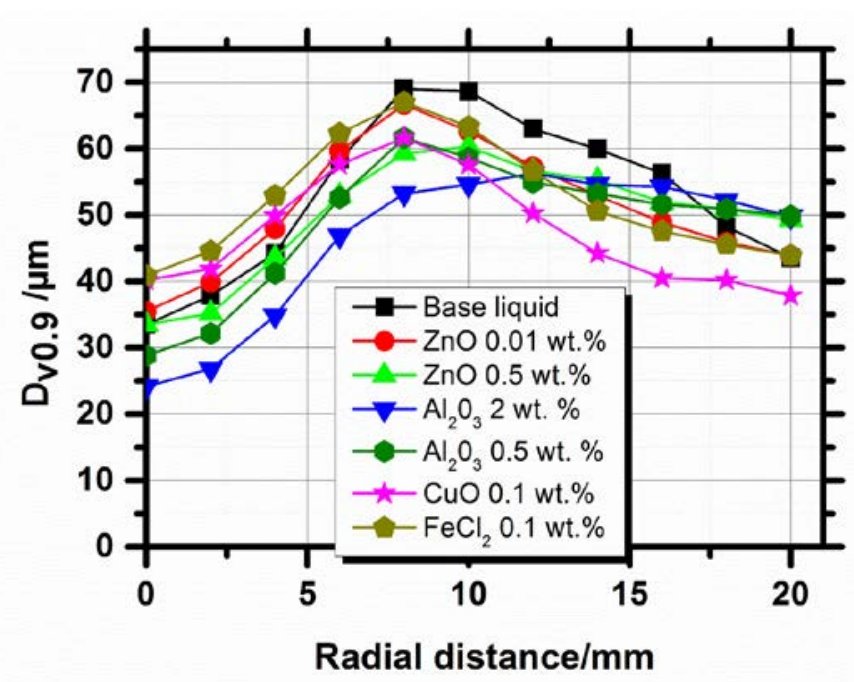

b)

Fig. 8 Spray profile characteristics measured at $Z=20 \mathrm{~mm}$ : a) $D_{V 0.1 .,}$ b) $D_{V 0.9}$.

To deeply evaluate the drop-size distribution in the single measured positions, the cumulative droplet volume fraction was calculated and plotted against the droplet size at two different radial distances. In the position $r=2 \mathrm{~mm}$ from the spray centre, the nanofluids with higher nanoparticle concentration formed a larger number of small droplets and thus a lower $D_{32}$, as shown in Fig. 9. No significant difference was observed between the nanofluids with different material particles. Hence, the nanoparticle material does not affect the characteristics of the resulting nanofluid spray. A similar trend is observed when analysing the measurements performed in radial positions further from the spray centre, even when the overall $D_{32}$ of all liquids is almost the same. The number of the small particles is lower here due to higher overall $D_{32}$. Droplets smaller than $50 \mu$ m contain $39 \%$ liquid volume for the nanofluid produced with the $\mathrm{Al}_{2} \mathrm{O}_{3}$ particles, which is higher than $26 \%$ obtained for the base liquid. 


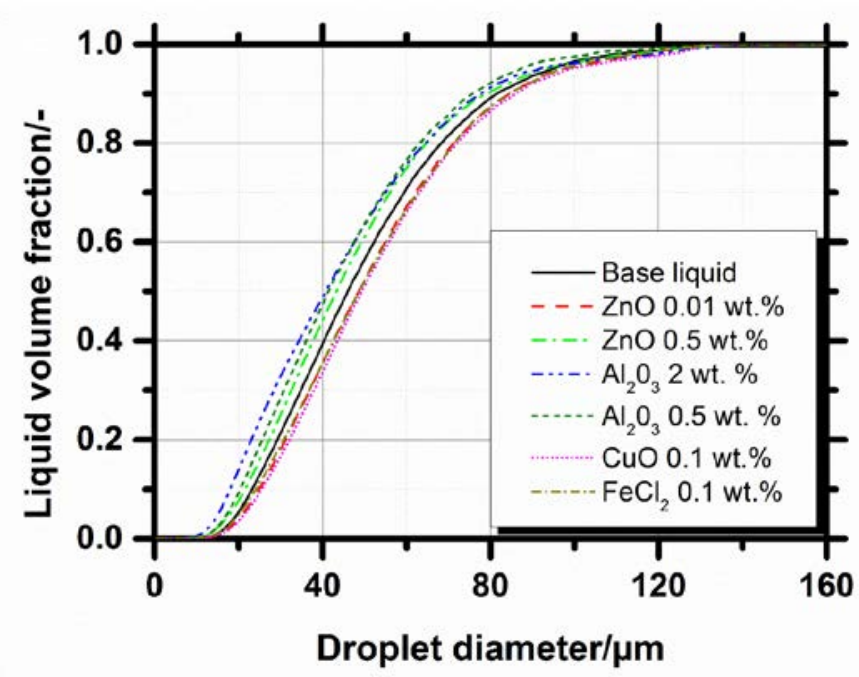

a)

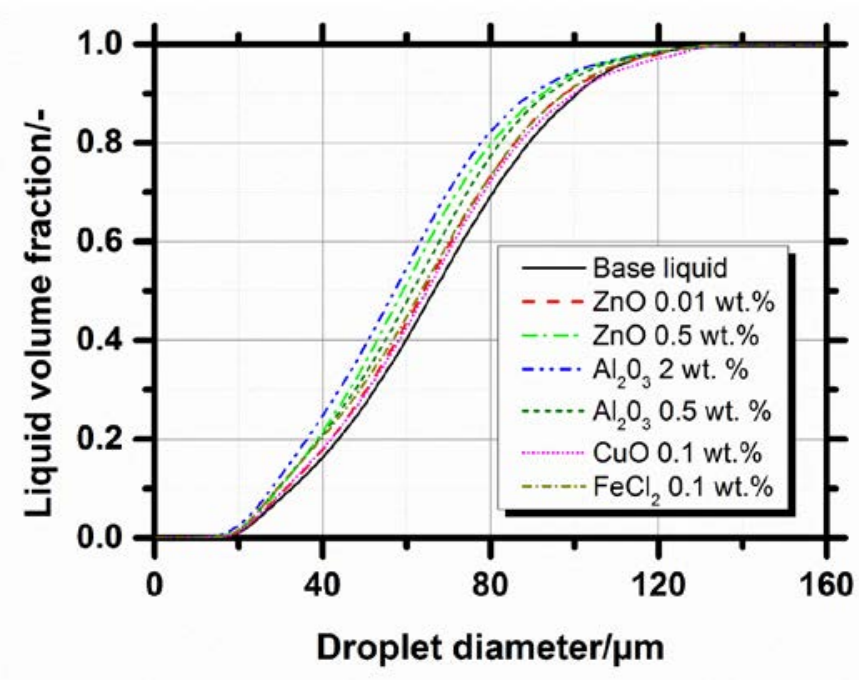

b)

Fig. 9 Cumulative liquid volume fraction evaluated at $Z=20 \mathrm{~mm}$. Measurements are taken at: a) $r=2 \mathrm{~mm}$ and b) $r=12 \mathrm{~mm}$.

To explain the velocity and size profiles, the droplet dynamics has to be considered. The droplets, formed from the liquid sheet, interact with surrounding air by transforming their momentum to the air and inducing its motion [41]. This process intensifies with increasing droplet surface [42], so it is more effective for sprays with smaller $I D_{32}$ like the 2 wt $\% \mathrm{Al}_{2} \mathrm{O}_{3}$, than for those depicting larger $I D_{32}(0.1 \mathrm{wt} \%$ 


\section{$\left.\mathrm{FeCl}_{2} \cdot 4 \mathrm{H}_{2} \mathrm{O}\right)$.}

This entrained air flows through the spray cone towards the centreline in the downstream direction. It causes a redistribution of the smallest droplets from the outer spray regions to the centreline. This effect explains three outcomes: 1) The generally high number of small droplets present in the centreline, that should have been, for the hollow-cone spray, free of droplets; 2) the difference between the shapes of the size profiles of individual liquids (Fig. 6b, Fig. 8). If a higher number of small droplet fraction shifts to the spray centreline, the outer spray part contains mainly the large droplets and the $D_{32}$ keeps high. 3) The droplets decelerate preferably in the axial direction, which causes widening of the SCA. This is documented in Fig. 7, where the $2 \mathrm{wt} \% \mathrm{Al}_{2} \mathrm{O}_{3}$ shows the liquid volume spread over larger radial positions when compared with 0.1 wt $\% \mathrm{FeCl}_{2} \cdot 4 \mathrm{H}_{2} \mathrm{O}$.

Despite this trend of the nanofluid sprays with higher particles concentration to form smaller droplets near the spray centre, with increased viscosity, the nanofluids form sprays with larger droplets due to larger droplets in position downstream the disintegrated liquid sheet, as clearly evidenced for $Z=10 \mathrm{~mm}$ in Fig. 10, which depicts the Integral Sauter Mean Diameter $I D_{32}$ as a function of the dynamic viscosity. This effect is less evident for fully developed spray at $Z=20 \mathrm{~mm}$ where the $I D_{32}$ varies in poor correlation with $R^{2}=0.27$ as $I D_{32} \sim \mu_{l}{ }^{0.16}$. This correlation has similar exponent as in [43] where a very similar atomizer was tested over a very wide viscosity range of oil-based fuels. For the simplex atomizers, other published data (e.g. as reviewed in [29] and [44]) reported several correlations varying from $I D_{32} \sim \mu_{l}^{0.118}$ to $I D_{32} \sim \mu_{l}^{0.25}$, depending on the atomizers and liquids used. For a given range of viscosities, the change in $I D_{32}$ is thus expected to be less than $2 \mu \mathrm{m}$ which is smaller than the measurement uncertainty. [30] also observed shorter breakup length of the liquid with high nanoparticle concentration. 
The SCA was observed to decline with the increase of the nanofluids viscosity for $Z=10 \mathrm{~mm}$; however, virtually no effect was found at $Z=20 \mathrm{~mm}$ (Fig. 11). Increasing viscous forces tends to lower the velocities inside the swirl chamber, thus causing the SCA to decrease. Data reported in [29] reveals that the SCA slightly decreases with viscosity as $S C A \sim \mu I^{-0.13}$, which should result in only a decline by about $1^{\circ}$ in the SCA, in this case. However, it is difficult to detect this small change which is below the measurement uncertainty. These results are in agreement with those observed in [29].

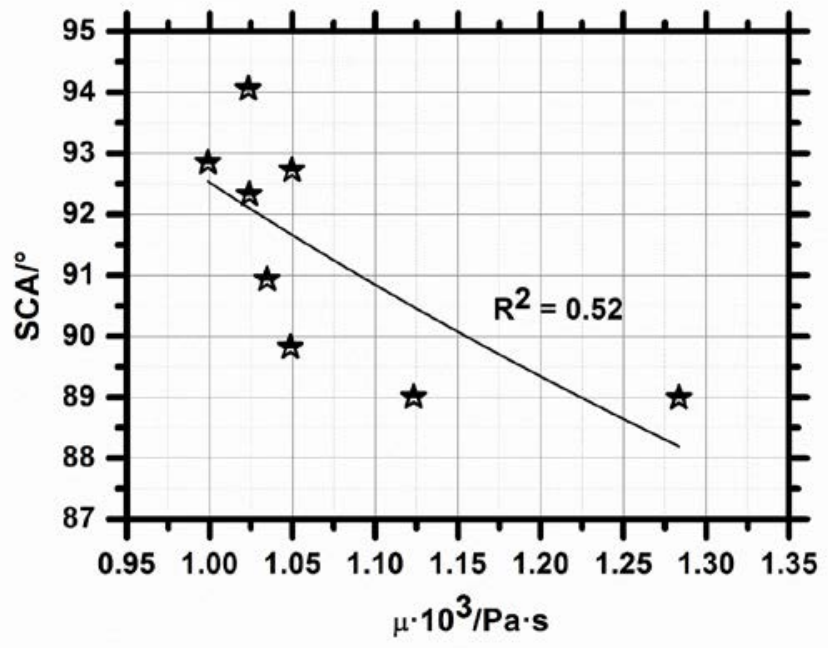

a)

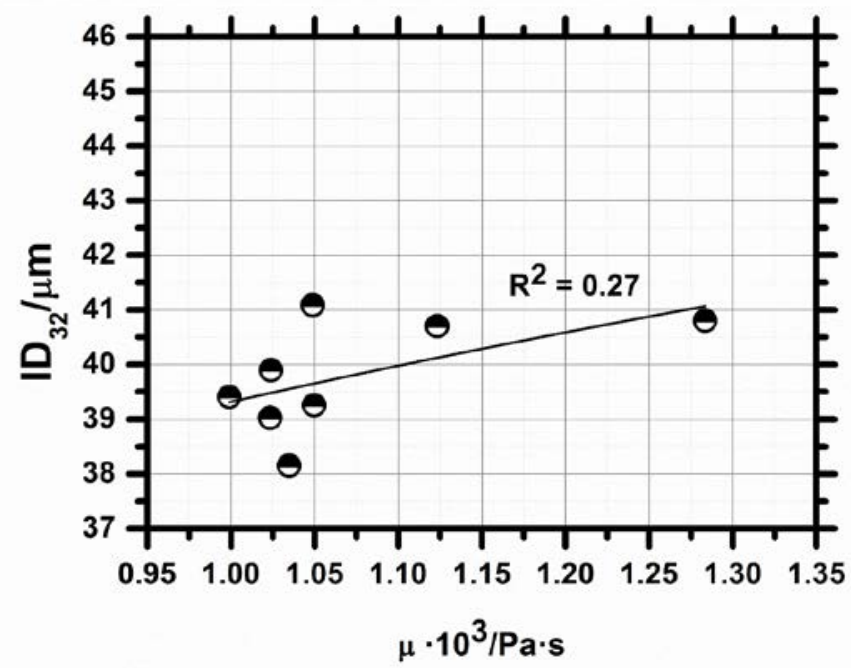

b) 
Fig. 10 Effect of the nanoparticles concentration (represented in the nanofluids viscosity) on the characteristic size of the spray droplets. PDA measurements performed at a) $Z=10 \mathrm{~mm}$. b) $Z=20 \mathrm{~mm}$.

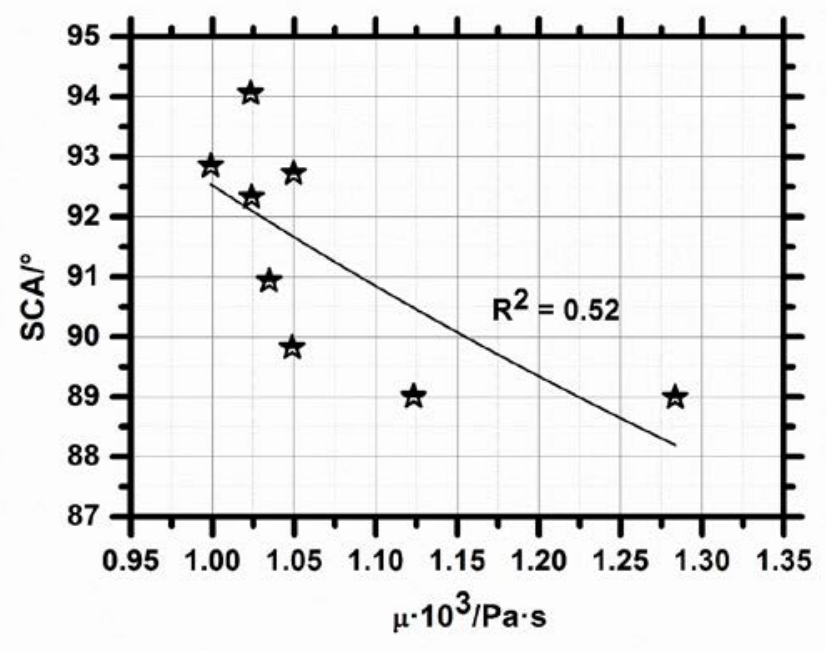

a)

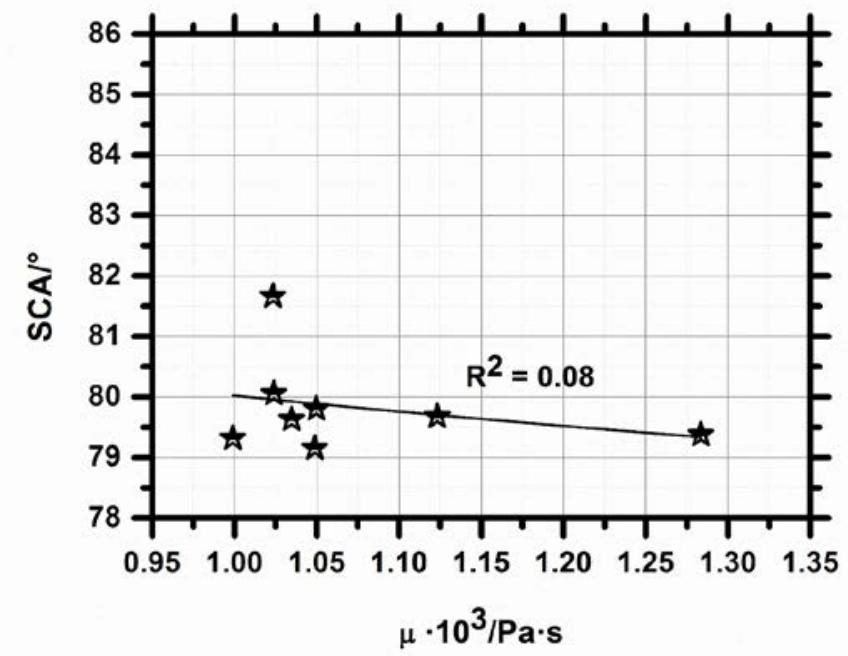

b)

Fig. 11 Effect of the nanoparticles concentration (represented in the nanofluids viscosity) on the SCA at a) $Z=10 \mathrm{~mm}$. b) $Z=20 \mathrm{~mm}$.

Two forces act against the liquid disintegration: surface tension and viscosity. A relative importance of viscous and surface tension forces can be estimated by the ratio of the liquid phase Weber (ratio between the surface tension and inertial forces) and Reynolds (ratio between the inertial and viscous forces) numbers at the nozzle exit [45]: We/ $\operatorname{Re}=w \cdot \mu / \sigma$ 
where $w$ is the liquid velocity at the exit orifice. It is mainly this ratio that gives the relative importance of the surface tension and the viscous forces. For our cases, this ratio is roughly 0.35-0.5, depending on the nanofluid used. This value, much smaller than unity, suggests the dominance of the surface tension forces over the viscous forces during the spray formation. Hence, it partially explains why the change in viscosity has a very small effect on the droplet sizes for $Z=20 \mathrm{~mm}$. On the other hand, the liquid sheet breakup during the primary breakup is affected mostly by the viscosity [29] as the measurements analysed for $Z=10 \mathrm{~mm}$ show a strong dependence on the viscosity. This also indicates that the liquid breakup is not completely finished at $Z=10 \mathrm{~mm}$.

Up to this point, the analysis has mainly focused on the spray characteristics and how they are affected by the nanoparticle concentration. The spray characteristics are intricately related to the cooling performance of the spray. In this context, one of the most obvious characteristics affecting the heat transfer is the SCA. The results analysed in the previous paragraphs show a trend for the higher nanoparticles concentration to mildly reduce the SCA at the exit of the nozzle orifice, due to the increase of the nanofluid viscosity. However, as also explained, this effect is fainted approximately at $20 \mathrm{~mm}$ below the atomizer orifice, so to avoid any influence on the spray wetted area and consequently on the heat flux one can mainly recommend the atomizer to be positioned at $20 \mathrm{~mm}$ or higher from the surface to cool.

Relating the spray mechanisms and characteristics with its cooling performance is far more complex and the detailed evaluation of the cooling performance of the spray must be analysed upon its impingement on the surface to cool. However, one may predict the contribution of the spray characteristics a priori to the cooling performance. The mechanism explained in the previous paragraphs leading to the appearance of smaller droplets at the centre of the spray region, which is more likely 
to occur in sprays with smaller $\mathrm{ID}_{32}$ like the $2 \mathrm{wt} \% \mathrm{Al}_{2} \mathrm{O}_{3}$ actually contributes to distribute the sprays droplets on the surface area, allowing a more homogeneous wetting and cooling. The heat fluxes to dissipate depend on the application that is being considered, but, for instance for electronic cooling, they easily achieve heat fluxes up to $1 \mathrm{MW} \cdot \mathrm{m}^{-2}$, which is enough for the impinging liquid to boil. If the injection period is large enough to create a liquid film, the pinching of the droplets contributes to the renovation of the cooling liquid on the surface, in a cooling process that is majorly convective and possibly occurring without phase change [1,32-33], which is precluded by this mechanism, as the local cooling precludes the occurrence of a stable nucleate boiling regime. While this mechanism is more effective depending on the inertial effects [2,32], which are higher for larger droplets, the fact that these sprays have smaller droplets may actually be beneficial, since splashing and interaction mechanisms, which take the fluid away from the surface, are less likely to occur [2,32]. If the injection period is not high enough to create a liquid film upon impingement, the cooling occurs as the spray droplets impact and spread on the surface. The size and velocity of the spray droplets directly influences the possible outcomes, as they impact on the surface, namely they can stick on the surface and spread along a thin liquid film called lamella, or they can break up, if the inertial forces at impact are high enough to overcome surface tension forces $[2,46]$. There are several criteria to establish the critical conditions for the occurrence of this immediate droplet disintegration upon impact, but the majority of them is a function of the Weber number, which is usually reported to be larger than 250, for the occurrence of disintegration, e.g. [32]. In the present study and particularly for the nanofluids with the smaller $I D_{32}$ the Weber number is always lower than this critical value, thus the spray droplets are more likely to stick and spread on the surface, contributing to the 
convective heat transfer, than to disintegrate, taking away the liquid mass from the surface. Also, under this scenario, as the droplets spread on thin lamellas of the liquid film, they are more likely to vaporize, thus allowing to take advantage of the latent heat of evaporation to cool the surface.

\section{Conclusions}

This paper addresses the effect of nanoparticles concentration on the characteristics of nanofluid sprays, which in turn may affect the spray performance in cooling applications. Different particles were added to water-based mixtures within a range of concentrations varying between $0.01 \%$ wt and $2 \%$ wt. The particles are mainly alumina, zinc, copper and iron oxides.

The liquid viscosity was found to be an important parameter in predetermining the spray characteristics of the nanofluids, as it affects the primary breakup. On the other hand, surface tension was found to be a dominant force in the break-up process.

However, for the range of nanoparticle concentrations studied here, the thermophysical properties of the nanofluids were not significantly changed in comparison to the base fluid. Hence, only a mild increase was detected in nanofluids viscosity, mainly observed for higher concentrations of alumina, which was not sufficient to affect the spray characteristics, except for a small decrease in the cone angle of the spray and in the diameter of the atomized droplets. However, the differences were in the same order of magnitude as the measurement uncertainty. Hence, for the conditions studied here, the addition of the nanoparticles positively contributes to the spray cooling performance as they may alter the thermal properties of the resulting nanofluid without significantly affect the hydrodynamic spray characteristics. The results also suggest that further investigation should be focused on very high particle concentrations, as the liquid physical properties 
will be influenced in a more significant way. In this context, the analysis of spray/surface interactions will also provide complementary information of the cooling performance of the resulting nanofluid sprays.

\section{Acknowledgements}

This work has been supported by the project No. 18-15839S funded by the Czech Science Foundation.

The authors are also grateful to Fundação para a Ciência e Tecnologia (FCT) for partially financing the research under the framework of the project RECI/EMS-SIS/0147/2012 and for supporting M. Maly with a research fellowship, during his stage at IN+. A. S. Moita acknowledges FCT for financing her contract and exploratory research project through the recruitment programme FCT Investigator (IF 00810-2015).

\section{References}

1. Kim, J. Spray cooling heat transfer: The state of the art. Int. J. Heat Fluid Flow. 2007;28(4):753-767.

2. Moreira, A. L. N., Moita, A. S. and Panão, M. R. Advances and challenges in explaining fuel spray impingement: how much of single droplet impact research is useful? Progress Energy and Combustion Sci. 2010;36:554-580.

3. Mahian, O, Kianifar, A., Kalogirou, S. A., Pop, I., Wongwises, S. A review of the applications of nanofluids in solar energy. Int. J. Heat Mass Transf. 2013;57:582594.

4. Bostanci, H., Daniel, R., John, K. and Louis, C. Spray cooling with ammonia on microstructured surfaces: performance enhancement and hysteresis effect. J. Heat Transf. 2009;131. 
5. Duursma, G., Sefiane, K. and Kennedy, A. Experimental studies of nanofluid droplets in spray cooling. Heat Transf. Eng. 2017;30(13):1108-1120.

6. Das, S. K., Choi,U.S., Yu, W., Pradeep, Y. Nanofluids: Science and Technology. Wiley, New Jersey, 2008.

7. Buongiorno, J., Venerus, D. C., Prabhat, N., McKrell, T., Townsend, J., Christianson, R., Tolmachev, Y. V., Keblinski, P., Hu, L.-w., Alvarado, J. L., Bang, I. C., Bishnoi, S. W., Bonetti, M., Botz, F., Cecere, A., Chang, Y., Chen, G., Chen, H., Chung, S. J., Chyu, M. K., Das, S. K., Di Paola, R., Ding, Y., Dubois, F., Dzido, G., Eapen, J., Escher, W., Funfschilling, D., Galand, Q., Gao, J., Gharagozloo, P. E., Goodson, K. E., Gutierrez, J. G., Hong, H., Horton, M., Hwang, K. S., Iorio, C. S., Jang, S. P., Jarzebski, A. B., Jiang, Y., Jin, L., Kabelac, S., Kamath, A., Kedzierski, M. A., Geok, L., Kieng, Kim, C., Kim, J.-H., Kim, S., Lee, S. H., Leong, K. C., Manna, I., Michel, B., Ni,R., Patel, H. E., Philip, J., Poulikakos, D., Reynaud, C., Savino, R., Singh, P. K., Song, P., Sundararajan, T., Timofeeva, E., Tritcak, T., Turanov, A. N., Van Vaerenbergh, S., Wen, D., Witharana, S., Yang, C., Yeh, W.-H., Zhao, X.-Z., Zhou, S.-Q. A benchmark study on the thermal conductivity of nanofluids. J. Appl. Phys. 2009;106:094312.

8. Chen, R.-H., Phuoc, T.X., Martello, D. Effects of nanoparticles on nanofluid droplets evaporation. Int. J. Heat Mass Transf. 2010;53:3677-3682.

9. Mehrali, M., Sadeghinezhad, E., Rashidi, M. M., Akhiani, A. R., Latibari, S. T., Mehrali, M., Metselaar, H. S. C. Experimental and numerical investigation of the effective electrical conductivity of nitrogen-doped graphene nanofluids. J. Nanoparticle Res. 2015; 17(6):267. 
10. Hsieh, S.-S., Liu, H.-H., Yeh, Y.-F. Nanofluids spray heat transfer enhancement, Int. J. Heat Mass Transf. 2016;94:104-118.

11. Esfe, M. H., Saedodin, S., Yan, W.-M., Afrand, M., Sina, N. Study on thermal conductivity of water-based nanofluids with hybrid suspensions of CNTs/Al2O3 nanoparticles. J. Therm. Anal. Calorim. 2016;124:455-460.

12. Selvam, C., Lal, D. M., Harish, S. Thermal conductivity and specific heat capacity of water-ethylene glycol mixture-based nanofluids with graphene nanoplatelets. J. Therm. Anal. Calorim. 2017;129:947-955.

13. Zyla, G. Viscosity and thermal conductivity of MgO-EG nanofluids: Experimental results and theoretical models predictions. J. Therm. Anal. Calorim. 2017;129:171-180.

14. Kakaç,S., Pramuanjaroenkij, A. A. Review of convective heat transfer enhancement with nanofluids. Int. J. Heat Mass Transf. 2009;52.3187-3196.

15. Nield, D. A., Bejan, A. Convection in Porous Media ( $4^{\text {th }}$ ed.). Springer, New York, 2013.

16. Kherbeet, A. Sh., Mohammed, H. A., Salman, B. H., Ahmed, H. E., Alawi, O. A., Rashidi, M. M., Experimental study of nanofluid flow and heat transfer over microscale backward- and forward-facing steps. Exp. Therm. Fluid Sci. 2015;65:13-21.

17. Shenoy, A., Sheremet, M. A., Pop, I. Flow and heat transfer past wavy surfaces: Viscous fluids, porous media and nanofluids, CRC Press, Taylor \& Francis Group, New York, 2016.

18. Sheikholeslami, M., Ganji, D. D. Nanofluid convective heat transfer using semi analytical and numerical approaches: A review. J. Taiwan Inst. Chem. Eng. 2016;65:43-77. 
19. Hosseinzadeh, M., Heris, S. Z., Beheshti, A., Shanbedi, M. Convective heat transfer and friction factor of aqueous $\mathrm{Fe} 3 \mathrm{O} 4$ nanofluid flow under laminar regime: An experimental investigation. J. Therm. Anal. Calorim. 2016;124:827-838.

20. Raei, B., Shahraki, F., Jamialahmadi, M., Peyghambarzadeh, S: M. Experimental study on the heat transfer and flow properties of c-Al2O3/water nanofluid in a double-tube heat exchanger. J. Therm. Anal. Calorim. 2017;127:2561-2575.

21. Akbari, O. A., Afrouzi, H. H., Marzban, A., Toghraie, D., Malekzade, H., Arabpour, A. Investigation of volume fraction of nanoparticles effect and aspect ratio of the twisted tape in the tube. $J$ Therm Anal Calorim (2017) 129:1911-1922.

22. Sharma, A. K., Tiwari, A. K., Dixit, A. R. Rheological behaviour of nanofluids: A review. Renewable Sustainable Energy Rev. 2016;53:779-791.

23. Vafaei, S., Borca-Tasciuc, T., Podowski, M. Z., Purkayastha, A., Ramanath, G., Ajayan, P. M. Effect of nanoparticles on sessile droplet contact angle. Nanotechnology. 2006;17: 2523-2527.

24. Wasan, D. T., Nikolov A D. Spreading of nanofluids on solids. Nature. 2003;423:156.

25. Chinnam, J., Das, D: K., Vajjha, R. S., Satti, J. R. Measurements of the surface tension of nanofluids and development of a new correlation. Int. J. Therm. Sci. 2015;98:68-80.

26. Jang, S. P., Lee, J.-H., Hwang, K. S., Choi, S. U. S. Particle concentration and tube size dependence of viscosities of water nanofluids flowing through microand minitubes. Appl. Phys. Lett.2007;91:243112. 
27. Ayela, F., Chevalier, J. Comment on "Particle concentration and tube size dependence of viscosities of water nanofluids flowing through micro- and minitubes" [Appl. Phys. Lett. 91, 243112 (2007)]. Appl. Phys. Lett. 2009;94:066101.

28. Singh, P. K., Harikrishna, P. V., Sundararajan, T., Das, S. K. Experimental and numerical investigation into the hydrodynamics of nanofluids in microchannels. Exp. Therm. Fluid Sci. 2012;42:174-186.

29. Lefebvre, A. H., McDonell, V. G. Atomization and sprays, $2^{\text {nd }}$ Edition, Taylor \& Francis, 2017.

30. Kannaiyan, K., Sadr, R. The effects of alumina nanoparticles as fuel additives on the spray characteristics of gas-to-liquid jet fuels. Exp. Thermal Fluid Sci. 2017;87:93-103.

31. Teodori, E., Moita, A. S., Pontes, P., Moura, M., Moreira, A. L. N., Y. Bai, X. Li, Y. Liu. Application of bioinspired superhydrophobic surfaces in two-phase heat transfer experiments. J. Bionic Eng. 2017;14(3):506-519

32. Panão, M. R. O., Moreira, A. L. N., Durão, D. F. G. Thermal-fluid assessment of multijet atomization for spray cooling applications. Energy. 2011;36: 23022311.

33. Panão, M. R. O., Moreira, A. L. N., Durão, D. F. G.Transient analysis of intermittent multijet sprays. Exp. Fluids. 2012;53:105-119.

34. Pastrana-Martínez, L.M., Pereira, N., Lima, R., Faria, J.L., Gomes, H.T., Silva, A.M.T. Degradation of diphenhydramine by photo-Fenton using magnetically recoverable iron oxide nanoparticles as catalyst. Chemical Eng. J. 2015;26:45-52.

35. Pereira P., Moita, A. S., Monteiro, G., Prazeres, D.M.F. Characterization of English weed leaves and biomimetic replicas. J. Bionic Eng. 2014;11(3):346-359. 
36. Moita, A. S., Teodori, E., Moreira, A. L. N. Enhancement of pool boiling heat transfer by surface micro-structuring, J. Phys.: Conf. Series. 2012;395:012175.

37. Moita, A.S., Laurência, C., Ramos, J.A., Prazeres, D.M.F., Moreira, A.L.N. (2016) Dynamics of droplets of biological fluids on smooth superhydrophobic surfaces under electrostatic actuation. J. Bionic Eng. 2016;13(2):220-234.

38. Jedelsky, J. Jicha, M. Energy considerations in spraying process of a spill-return pressure-swirl atomizer. App. Energy. 2014; 132: 485-495.

39. Manasse, U., Wriedt, T., Bauckhage, K. Phase-Doppler sizing of optically absorbing liquid droplets: Comparison between Mie theory and experiment. Particle and Spray Systems Characterization. 1992;9(1-4):176-185.

40. Albrecht, H.-E., Borys, M., Damaschke, N. Tropea, C. Laser Doppler and phase Doppler measurement techniques. Springer-Verlag Berlin, Heidelberg, Germany, 2003.

41. Santolaya, J. L., García, J. A., Calvo, E., Cerecedo, L. M. Effects of droplet collision phenomena on the development of pressure swirl sprays Int. J. Multiph. Flow. 2013;56:160-171.

42. Jedelsky, J., Maly, M., del Corral, M. O., Wigley, G., Janackova, L., Jicha, M. Air-liquid interactions in a pressure-swirl spray. Int. J. Heat and Mass Transf. 2018;121:788-804.

43. Maly, M., Janackova, L., Jedelsky, J., Jicha, M. Impact of alternative fuel rheology on spraying process of small pressure-swirl atomizer. AIP Conf. Proceedings. 2016;1745:020031.

44. Lefebvre, A. H. The prediction of Sauter mean diameter for simplex pressure-swirl atomisers. Atomization and spray technology, 1987;3(1):37-51. 
45. Yule, A. J., Dunkley, J. J. Atomization of melts for powder production and spray deposition Oxford, Clarendon Press, 1994.

46. Moita, A. S., Moreira, A. L. N. Experimental study on fuel drop impacts onto rigid surfaces: morphological comparisons, disintegration limits and secondary atomization. Proceedings of the Combustion Institute. 2007;31:2175-2183 